\title{
TEORES DOS METAIS PESADOS Cr, Cd E Zn EM PERFIS DE SOLOS DE VEREDAS DA BACIA DO RIO DO FORMOSO, MUNICÍPIO DE BURITIZEIRO, MINAS GERAIS
}

\author{
Priscilla Palmeiras Freitas de Moraes ${ }^{1} \&$ Adolf Heinrich Horn ${ }^{2}$
}

\begin{abstract}
Resumo
As concentrações dos elementos $\mathrm{Cr}$, $\mathrm{Cd}$ e $\mathrm{Zn}$ em amostras de solo (fração $<0,074 \mathrm{~mm}$ ) de três veredas selecionadas na Bacia do Rio do Formoso, município de Buritizeiro, Minas Gerais, foram determinadas para obter informações com relação à qualidade ambiental dos solos destas áreas. As amostras foram coletadas em perfis verticais e preparadas para as análises físico-químicas. As leituras das concentrações dos metais foram determinadas por ICP-OES e apresentaram níveis acima do permitido pela legislação, principalmente para os elementos $\mathrm{Cr}$ e $\mathrm{Cd}$.
\end{abstract}

PALAVRAS-CHAVE: metais pesados, solos, veredas, contaminação.

\begin{abstract}
The concentrations of $\mathrm{Cr}$, $\mathrm{Cd}$ and $\mathrm{Zn}$ in soil samples (fraction $<0.074 \mathrm{~mm}$ ) of three selected veredas in the basin of the Formoso River, Buritizeiro municipality, Minas Gerais, were determined to obtain information regarding the soils environmental quality of these areas. The samples were collected in vertical profiles and prepared for the physical-chemical analysis. The readings of concentrations of metals were determined by ICP-OES and showed levels above those permitted by law, particularly for elements $\mathrm{Cr}$ and $\mathrm{Cd}$.
\end{abstract}

KEYWORDS: heavy metals, soils, veredas, contamination.

\section{INTRODUÇ̃̃O}

Segundo Melo (1992), vereda constitui um tipo de ecossistema, que se desenvolve sob condições definidas de umidade em regiões de cerrados, sendo identificadas, em geral, como cabeceiras ou nascentes de rios. Boaventura (1978), por sua vez, conceitua vereda como uma depressão aberta, rasa e alongada, com vertentes suaves e fundo plano, com solos turfosos, permanentemente saturados por água de exsudação do lençol freático. A palmeira buriti (Mauritia flexuosa) é um elemento característico na vereda, ocorrendo tanto em alinhamentos que acompanham os pontos de maior umidade, como em formações mais densas que se destacam no meio dos cerrados adjacentes. A Bacia do Rio do Formoso possui inúmeras veredas e, por serem áreas úmidas, localizadas dentro do Bioma Cerrado que possui escassez deste recurso natural, sofrem interferência antrópica devido a atividades agrosilvopastoris desenvolvidas em seu interior e seus entornos.

Viana (2006) estudou as águas e o grau de contaminação e alteração das veredas da Bacia do Rio do Formoso e detectou contaminações por metais pesados em áreas de plantações e silvicultura, devido ao uso de agro-corretivos e agrotóxicos. Baggio (2008), estudando toda a Bacia do Rio do Formoso, confirmou esta contaminação antrópica de metais pesados em águas e sedimentos de corrente, principalmente na porção montante desta que possui áreas de atividade agrícola intensa.

O presente trabalho apresenta dados da distribuição dos metais pesados $\mathrm{Cr}$, Cd e $\mathrm{Zn}$ em perfis de solos de três veredas localizadas no município de Buritizeiro, com o objetivo de avaliar a situação ambiental atual destes ambientes com relação ao grau de contaminação por estes elementos. Tendo em vista que se trata de áreas próximas a atividades com fins agropecuários e de silviculturas esses elementos foram selecionados por serem liberados na decomposição de agroquímicos e fertilizantes, principais fontes antropogênicas de contaminação.

A Bacia do Rio do Formoso localiza-se na porção sudoeste do município de Buritizeiro (Figura 1) e é delimitada pelas coordenadas $16^{\circ} 30^{\prime}-18^{\circ} 00 \mathrm{~S} \mathrm{e} 45^{\circ} 40^{\prime}$ $-\mathrm{W}$, ocupando uma área de aproximadamente $826 \mathrm{~km}^{2}$.

As veredas selecionadas foram denominadas de Vereda Laçador, localizada na porção montante da Bacia; Vereda Jaraguá, localizada na porção central da Bacia e Vereda Urbano, localizada na porção jusante da Bacia (Figura 2).

A vereda Laçador localiza-se na Fazenda Conquista, BR $365, \mathrm{~km} 254$. As coordenadas geográficas em UTM desta vereda são 453366,20 e 8029821,00. A vegetação em seu entorno é de cerrado, com predomínio de capim vereda e há plantações de soja, milho e feijão na fazenda na qual se situa. A vereda se desenvolveu sobre rochas da Formação Chapadão, formado principalmente 

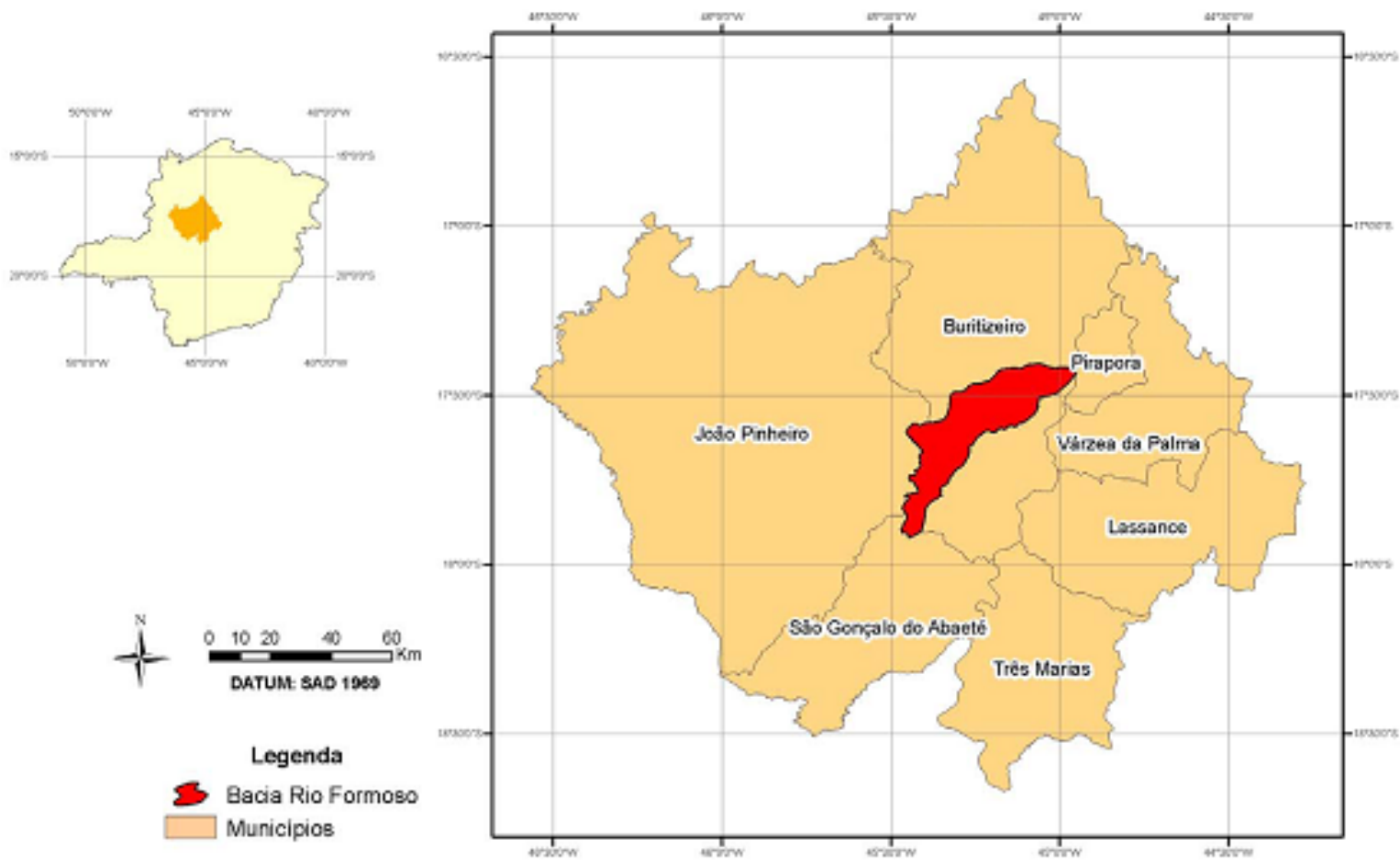

Figura 1: Localização da área de estudo da Bacia do Rio Formoso, situada no município de Buritizeiro no Estado de Minas Gerais (Viana, 2006).

por coberturas elúvio-coluviais. Com relação à compartimentação geomorfológica, encontra-se dentro das unidades de chapadas do Terciário (Baggio, 2008).

A vereda Jaraguá localiza-se na Fazenda Jaraguá, BR 365, km 196. As coordenadas geográficas em UTM desta vereda são 481811,12 e 8070286,56 . A vegetação em seu entorno é de cerrado com plantações de eucalipto (figura 3). A vereda se desenvolveu sobre rochas na interface dos Grupos Areado e Mata da Corda, formados principalmente por conglomerados fluviais e por arenitos eólicos e fluvio-deltáicos. Com relação à compartimentação geomorfológica, encontra-se dentro das unidades de colinas do Cretáceo Inferior (Baggio, 2008).

A vereda Urbano está localizada às margens da BR 365, km 178. As coordenadas geográficas em UTM desta vereda são 493772,83 e 8075518,63. A vegetação em seu entorno é de cerrado com predomínio de capim vereda. A mesma encontra-se descaracterizada fisicamente, devido à substituição de parte de sua vegetação original por pastagens (Figura 4). A vereda se desenvolveu sobre rochas do Grupo Bambuí do Neoproterozóico, formado principalmente pelos litotipos arcóseos, siltitos e argilitos de coloração violácea ou verde. Com relação à compartimentação geomorfológica, encontra-se dentro das unidades de colinas neoproterozóicas, rampas convexas com flancos ravinados e vales encaixados (Baggio, 2008).

A amostragem na Vereda Laçador foi realizada em maio de 2009, na Vereda Jaraguá, em fevereiro de
2009 e na vereda Urbano, em dezembro de 2008. Os resultados das análises geoquímicas foram comparados com os valores orientados da CETESB (2005) e CONAMA (2009).

\section{PROCEDIMENTOS METODOLÓGICOS}

\section{Campo}

Na vereda Laçador, coletaram-se amostras de solos em seis perfis pedológicos. Utilizou-se a cavadeira "boca de lobo" em todos eles, com exceção do Perfil 5 no qual utilizou-se um amostrador manual com cápsula coletora na sua extremidade e com hastes estendidas.

Na vereda Jaraguá, coletaram-se amostras em dois perfis pedológicos com o auxílio de uma cavadeira "boca de lobo".

Finalmente, na vereda Urbano retirou-se em duas trincheiras abertas, sete amostras em um perfil vertical, sendo as amostras coletadas com o auxílio de uma pá de plástico.

As amostras continham, aproximadamente, 0,5 a $1 \mathrm{~kg}$ de solo. O material foi acondicionado adequadamente e enviado para o laboratório NGqA do CPMTC-IGC, em Belo Horizonte, MG.

\section{Laboratório}

Em laboratório, as amostras foram secas à temperatura ambiente e, em seguida, destorroadas 


\section{Mapa Geológico da Bacia do Rio do Formoso}

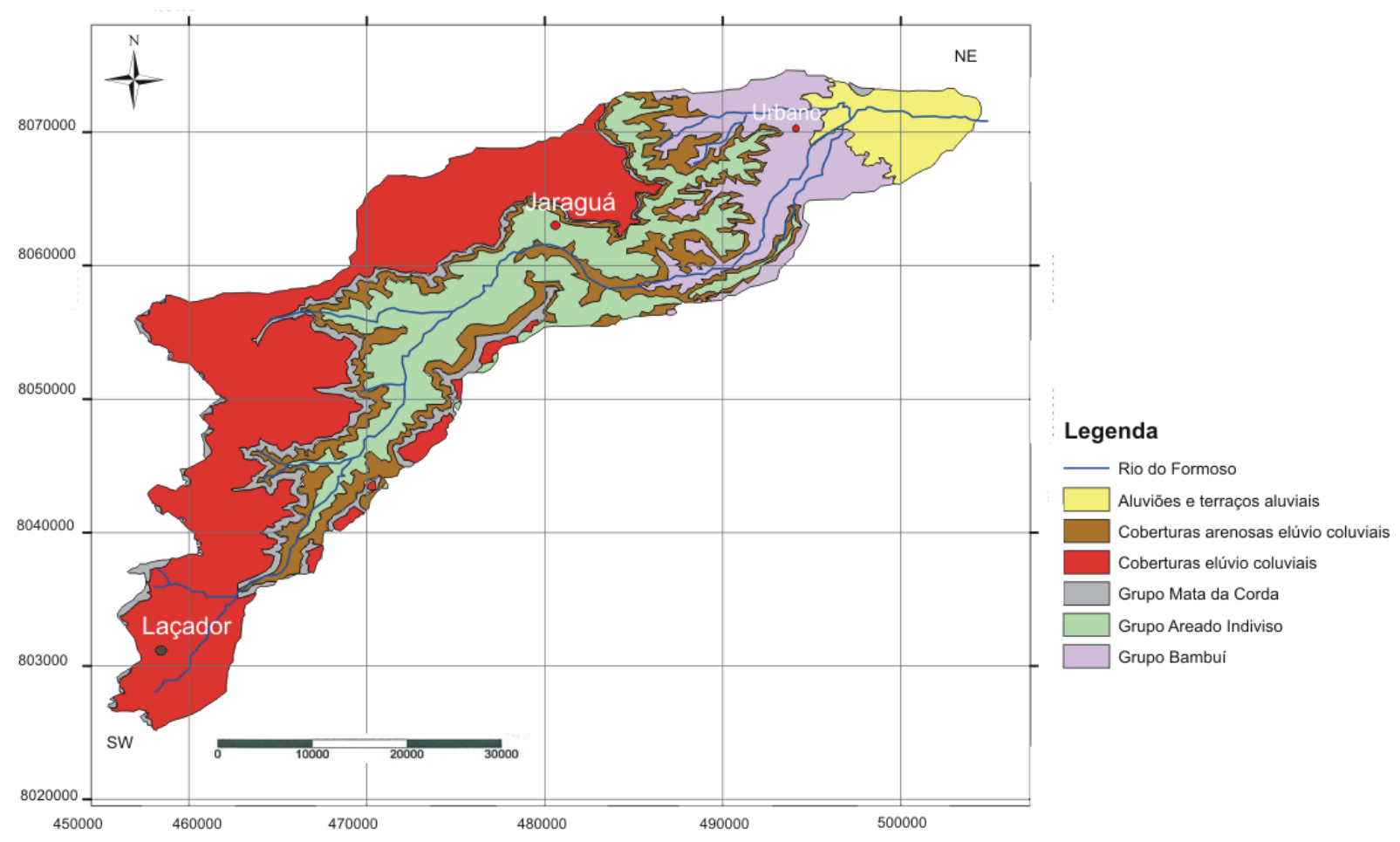

Figura 2: Localização das três veredas estudadas no mapa geológico da Bacia do Rio do Formoso. (Baggio, 2008, modificado).

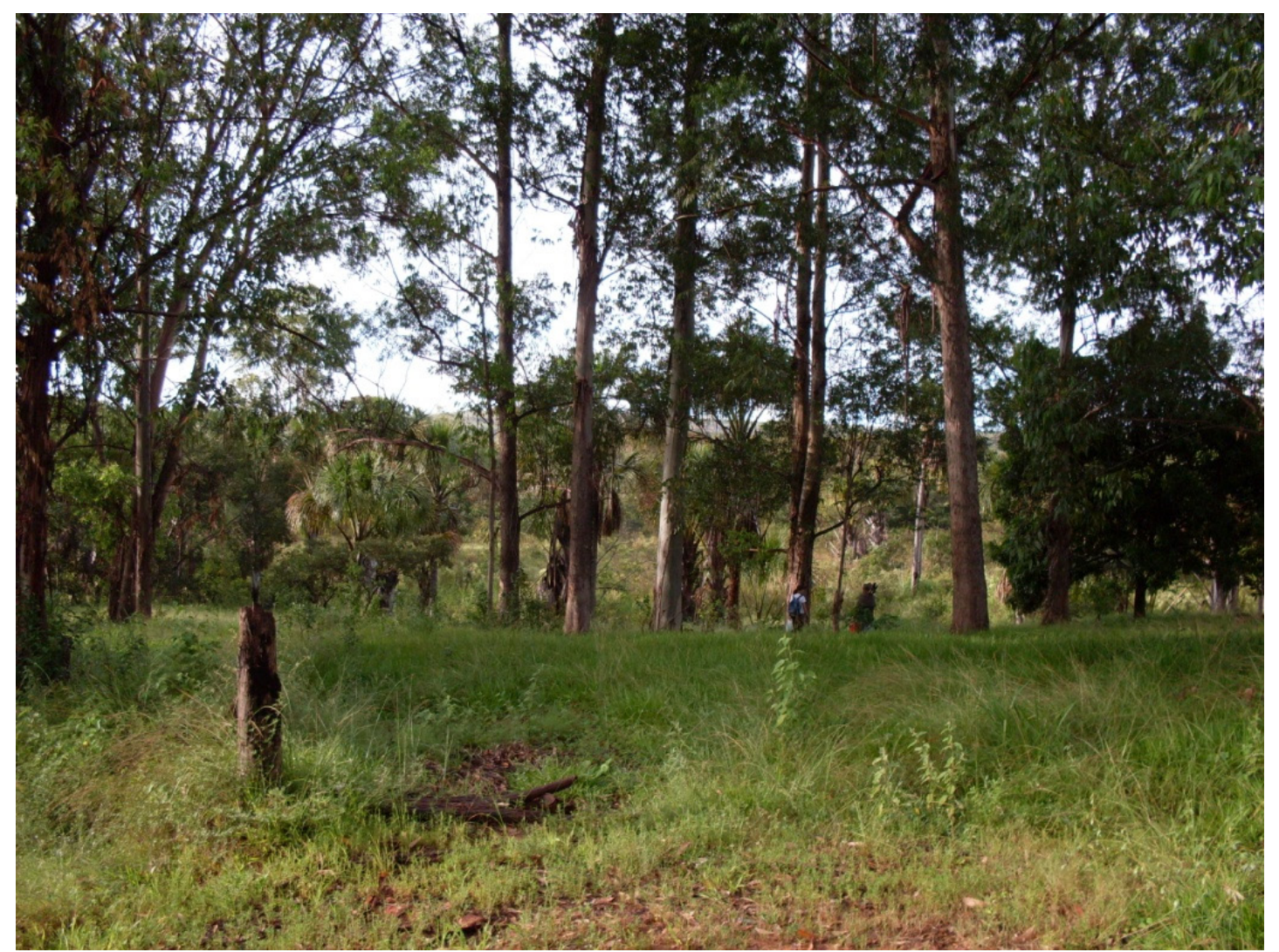

Figura 3: Plantio de eucaliptos à margem sudeste da zona encharcada da vereda Jaraguá. Nota-se claramente uma depressão central (atrás dos eucaliptos) com vegetação ainda preservada (buritis). 


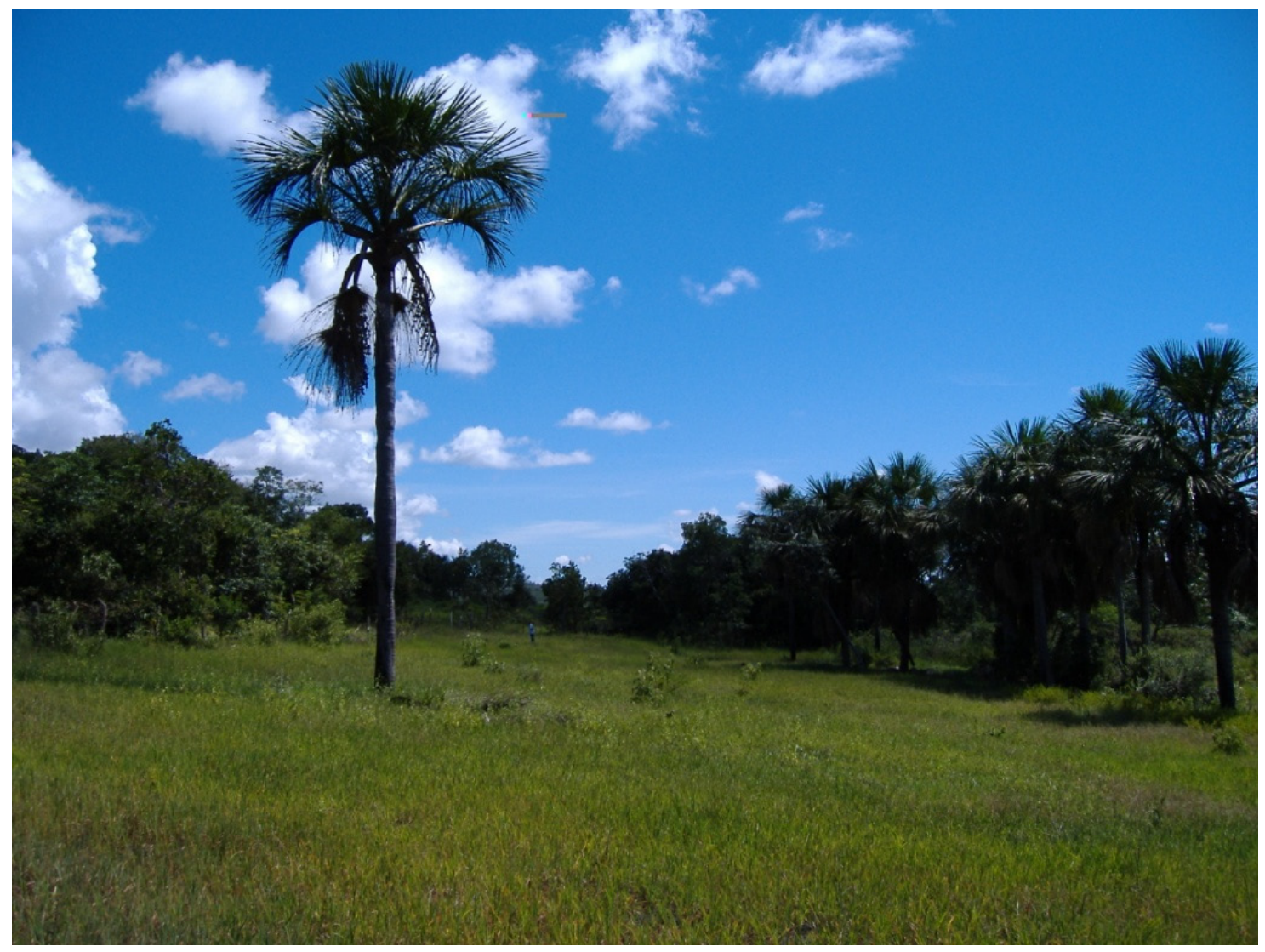

Figura 4: Vereda descaracterizada por longo período de uso como pastagem de gado. Localizada sobre a unidade geológica do Grupo Bambuí - Formação Três Marias. O anel de buritis indica o local onde há a maior quantidade de água no solo.

com a utilização de um martelo de borracha. As amostras foram, então, peneiradas para determinar a distribuição granulométrica e obter a fração mais fina $(<0,074 \mathrm{~mm})$ utilizada para a análise química, pesadas e homogeneizadas.

As análises foram realizadas no laboratório do NGqA do CPMTC-IGC-UFMG. A metodologia utilizada foi a digestão em microondas com ácido nítrico concentrado de acordo com a Agência de Proteção Ambiental dos Estados Unidos da América (U.S. EPA,1994) método 3051-16, o qual segue descrito.

Pesou-se $0,5 \mathrm{~g}$ de amostra em balança analítica e colocou-se em tubos de ensaio de teflon, adicionouse $10 \mathrm{~mL}$ de ácido nítrico concentrado e levou-se ao forno de microondas MarsXpress da CEM por 25min. Deixou-se em repouso as amostras por 30 minutos para resfriamento e procedeu-se a transferência das mesmas para um balão volumétrico de $50 \mathrm{~mL}$, completando-se com água deionizada o volume dos mesmos. Após filtragem em micropore $0,45 \mu \mathrm{m}$ as soluções foram enviadas para a leitura em ICP-OES (aparelho modelo M 4165 - Epectroflame - Spectro). Foram medidos os teores dos elementos $\mathrm{Cr}$, $\mathrm{Cd}$ e $\mathrm{Zn}$.

Para a determinação do $\mathrm{pH}$ das amostras de solo utilizou-se a metodologia de $\mathrm{pH}$ em água segundo Embrapa (1997). A leitura do $\mathrm{pH}$ foi feita em triplicatas. Para realizar o procedimento, ligou-se o potenciômetro
30 minutos antes de começar a ser usado e aferiu-se o mesmo com as soluções padrão $\mathrm{pH}$ 4,00 e 7,00. Em seguida, colocou-se $10 \mathrm{~mL}$ de solo em copo plástico de $100 \mathrm{~mL}$. Adicionou-se $25 \mathrm{~mL}$ de água. Agitou-se a amostra com bastão de vidro individual e deixou em repouso por uma hora. A seguir, agitou-se cada amostra com bastão de vidro, mergulhou os eletrodos na suspensão homogeneizada e procedeu-se a leitura de $\mathrm{pH}$.

\section{RESULTADOS E DISCUSSÃO}

A Tabela 1 informa a denominação das amostras de acordo com a Vereda indicada nas figuras 5, 6 e 7, onde são mostradas em detalhe os perfis das Veredas Laçador, Jaraguá e Urbano, respectivamente.

$\mathrm{Na}$ Vereda Laçador foram realizados 6 perfis de amostragem e nas Veredas Jaraguá e Urbano, 2 perfis cada.

As amostras de solos nas Veredas Laçador, Jaraguá e Urbano indicaram valores de $\mathrm{pH}$ entre 1,21 e 6,97. Em sua maioria, os valores determinados são típicos de solos ácidos ou fortemente ácidos. Tais condições, de modo geral, favorecem a solubilização e mobilização de metais pesados na solução do solo, e por extensão, as perdas desses elementos por lixiviação.

Os valores de $\mathrm{pH}$ abaixo de 2,5-3,0 (solos fortemente 


\begin{tabular}{|c|c|}
\hline Denominação Amostra & Vereda \\
\hline V1 & Laçador \\
\hline V2 & Jaraguá \\
\hline V3 & Urbano \\
\hline
\end{tabular}

Tabela 1: Denominação das amostras de acordo com a Vereda pertencente. ácidos) são resultados da presença de ácidos húmicos e fúlvicos na matéria orgânica das amostras.

Os teores de metais pesados são apresentados nas tabelas 2, 3 e 4 para as amostras de solo das veredas Laçador, Jaraguá e Urbano, respectivamente. Como referencial de análise fez-se uso dos valores orientadores da CETESB (CETESB, 2005) para os

SE NE

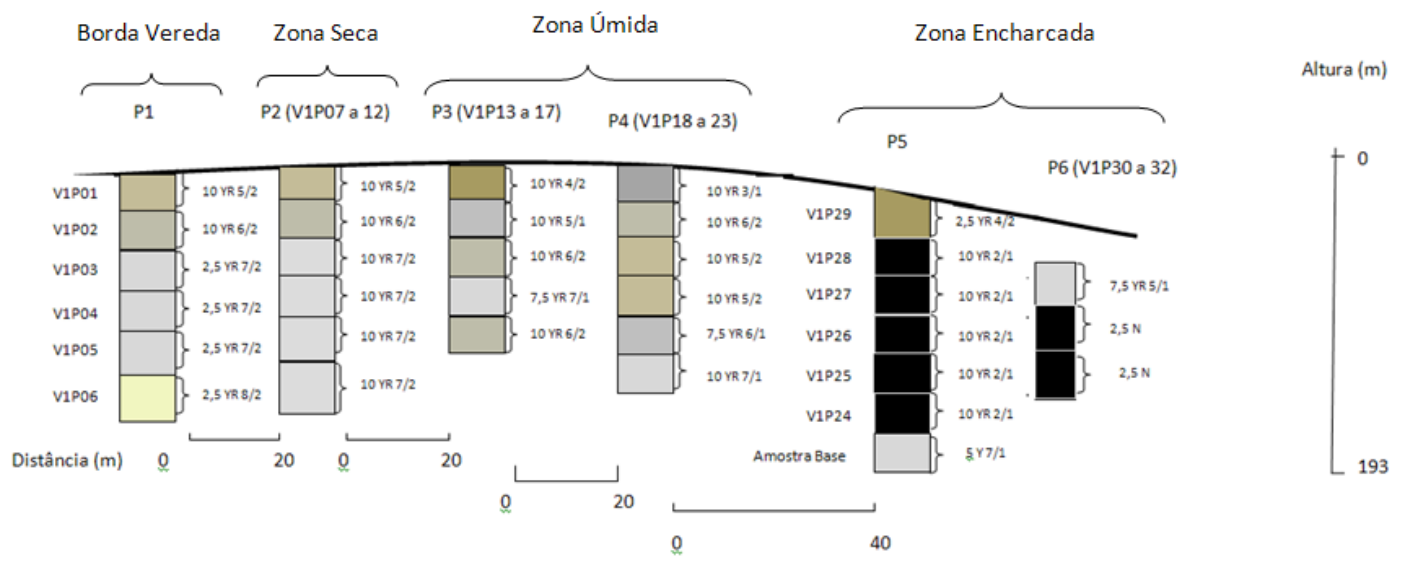

Figura 5: Detalhamento dos Perfis 1 a 6 da Vereda Laçador. A caracterização de cor das amostras de solo foi feita utilizando-se a Munsell Soil Color Charts. Na vereda Laçador, as caracterizações da cor variaram de $5 Y$ (cinzento claro) a 2,5 N (preto), tratando-se de colorações típicas de solos mal drenados.

W

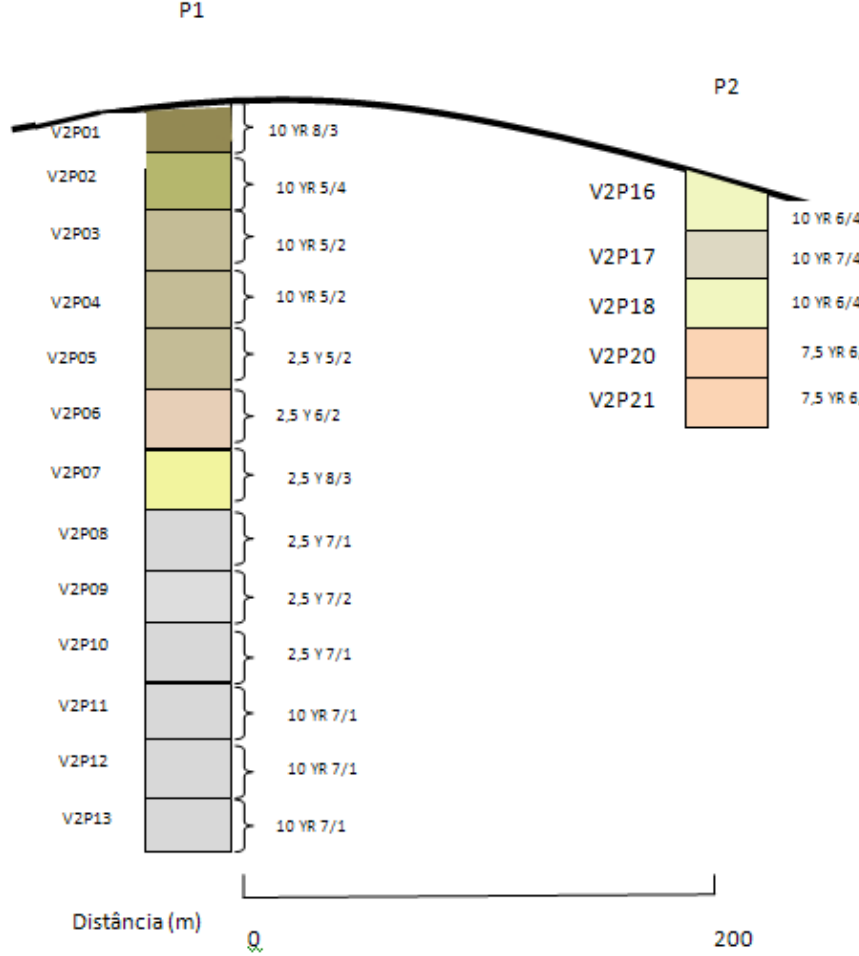

Altura $(\mathrm{cm})$

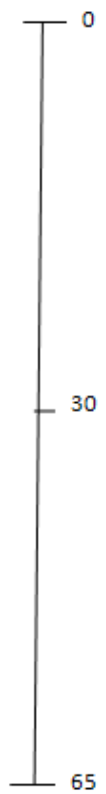

Figura 6: Detalhamento dos Perfis 1 e 2 da Vereda Jaraguá. A caracterização de cor das amostras de solo foi feita utilizando-se a Munsell Soil Color Charts. Na vereda Jaraguá, as caracterizações da cor variaram de 2,5Y (cinzento claro) a 10 YR (bruno acinzentado), tratando-se de colorações típicas de solos mal drenados. 


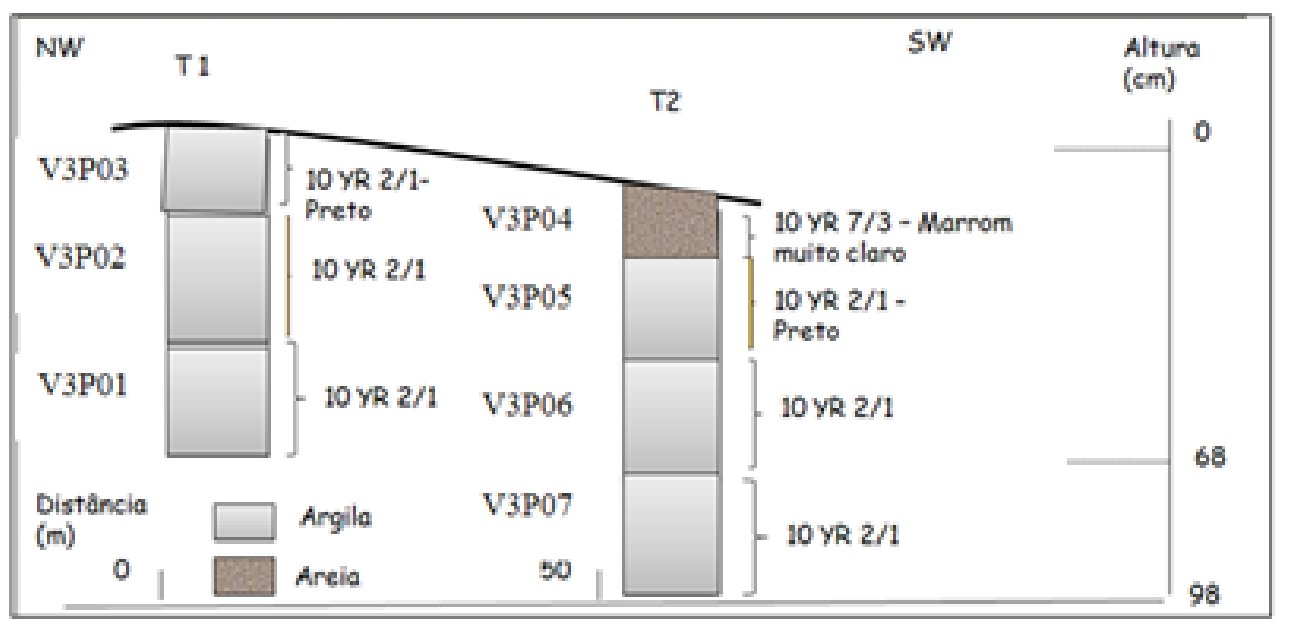

Figura 7: Detalhamento dos Perfis 1 e 2 da Vereda Urbano. A caracterização de cor das amostras de solo foi feita utilizando-se a Munsell Soil Color Charts. Na vereda Urbano, as caracterizações da cor variaram de 10 YR 7/3 (bruno muito claro-acinzentado) a 10 YR 2/1 (preto), tratando-se de colorações típicas de solos mal drenados.

limites de referência de qualidade e da Resolução CONAMA 420/2009 para os valores de prevenção e intervenção.

$\mathrm{Na}$ Vereda Laçador, chama a atenção os valores encontrados para os elementos cromo e cádmio, pois ultrapassam, em todas as amostras os valores de referência de qualidade, tendo, em algumas amostras ultrapassado os valores de prevenção e intervenção. O zinco também ultrapassou o valor de qualidade em duas amostras.

Esta vereda está localizada à montante da Bacia em área destinada ao plantio comercial de grãos, onde se faz o uso intensivo de fertilizantes, inseticidas e herbicidas fosfatados, como também de corretivos de solos contendo zinco e agrotóxicos, cujo componente ativo contém sais de Zn (Kiekens, 1990). Portanto, o teor elevado deste metal pode refletir uma contribuição antropogênica.

O teor de cádmio indica contribuição antropogênica porque apresentou-se mais elevado em amostras superficiais (0-20 cm) e Baggio (2008) observou teores elevados desse elemento nos sedimentos de fundo/ corrente no alto curso do Rio do Formoso, porção montante da Bacia, na qual se localiza esta vereda e onde o uso do solo agrícola se faz de maneira intensiva. Além disso, este mesmo autor encontrou teores de $\mathrm{Cd}$, nos litotipos arenitos e argilitos desta Bacia, abaixo dos valores para arenito e folhelho médios, tomando como referência os valores de Bowen (1979) e Krauskopf (1976) e abaixo dos teores encontrados no presente trabalho.

O teor de cromo também indica contribuição antropogênica, pois Baggio (2008) não constatou valores deste elemento, nos litotipos arenitos e argilitos da Bacia, acima dos valores de referência estabelecidos por Bowen (1979) e Krauskopf (1976). Além disso, os valores deste elemento encontrados por Baggio (2008) nos litotipos da Bacia estão abaixo dos valores encontrados no presente estudo e o mesmo autor encontrou teores elevados em amostras de sedimento de fundo/corrente no alto curso do Rio do Formoso, onde se encontra esta vereda. $\mathrm{O}$ aumento apresentado nos teores de $\mathrm{Cr}$ pode estar associado à sua utilização como agente ativo das tintas, que são utilizadas na preservação do madeirame, empregado na construção de cercas, galpões e nas casas. Além disso, a intensa utilização de agroquímicos contendo anidrito crômico, ácido crômico, óxido crômico e trióxido de cromo utilizados no plantio de grãos. Os resíduos metalo-orgânicos secos e/ou pulverizados são transportados pelo ar e pela água de irrigação e depositados nos solos.

Na Vereda Jaraguá, os teores de cromo ultrapassaram o limite de referência de qualidade na maioria das amostras, tendo ultrapassado o limite de prevenção em algumas delas e o limite de intervenção em uma amostra. Os teores de cádmio ultrapassaram o valor de referência de qualidade na totalidade das amostras.

O elevado teor de cromo e cádmio na Vereda Jaraguá também é proveniente de contribuição antropogênica pelas mesmas razões mostradas anteriormente na vereda Laçador, uma vez que os valores encontrados para estes elementos em litotipos desta Bacia são inferiores aos encontrados nos solos estudados no presente trabalho. As fontes de cromo na Vereda Jaraguá são as que foram mostradas na Vereda Laçador e os elevados teores de cádmio nos solos desta vereda são provenientes do uso agrícola de fertilizantes fosfatados contendo este elemento.

Com relação aos teores dos elementos analisados na Vereda Urbano, chama a atenção os teores de cromo que ultrapassaram o limite de referência de qualidade na quase totalidade das amostras, tendo ultrapassado o valor de prevenção em duas amostras e de intervenção em uma amostra. Os teores de cádmio ultrapassaram os limites de referência de qualidade na totalidade das amostras e os teores de zinco ultrapassaram o limite de 


\begin{tabular}{|c|c|c|c|c|}
\hline \multicolumn{5}{|c|}{ Vereda Laçador - Uso do solo: Agricultura } \\
\hline Amostra & \begin{tabular}{|c|} 
Profundidade \\
(cm)
\end{tabular} & $\mathrm{Cr}$ & Cd & $\mathbf{Z n}$ \\
\hline & & \multicolumn{3}{|c|}{$\mathrm{mg} / \mathrm{kg}$} \\
\hline V1P01 & $0-20$ & $127,8^{\mathrm{P}}$ & $1,2^{Q}$ & $70,8^{Q}$ \\
\hline V1P02 & $20-40$ & $114,3^{P}$ & $0,8^{Q}$ & 17,7 \\
\hline V1P03 & $40-60$ & $118,1^{\mathrm{P}}$ & $1,2^{Q}$ & 13,3 \\
\hline V1P04 & $60-80$ & $114,9^{P}$ & $1,0^{\mathrm{Q}}$ & 12,1 \\
\hline V1P05 & $80-100$ & $102,7^{P}$ & $0,7^{\mathrm{Q}}$ & 10,2 \\
\hline V1P06 & $100-127$ & $97,3^{P}$ & $1,1^{\mathrm{Q}}$ & 8,9 \\
\hline V1P07 & $0-17$ & $133,7^{P}$ & $1,3^{Q}$ & 58,8 \\
\hline V1P08 & $17-34$ & $128,2^{P}$ & $1,3^{Q}$ & 25,3 \\
\hline V1P09 & $34-51$ & $135,9^{P}$ & $1,2^{\mathrm{Q}}$ & 15,2 \\
\hline V1P10 & $51-68$ & $114,7^{P}$ & $0,8^{Q}$ & 12,7 \\
\hline V1P11 & $68-85$ & $114,9^{P}$ & $1,1^{Q}$ & 15,5 \\
\hline V1P12 & $85-103$ & $155,6^{\prime}$ & $1,1^{\mathrm{Q}}$ & 12,6 \\
\hline V1P13 & $0-20$ & $148,7^{P}$ & $1,6^{P}$ & $80,1^{\mathrm{a}}$ \\
\hline V1P14 & $20-40$ & $140,2^{P}$ & $1,3^{Q}$ & 37,0 \\
\hline V1P15 & $40-60$ & 159,0 & $1,3^{Q}$ & 15,4 \\
\hline V1P16 & $60-80$ & 180,8 & $1,2^{\mathrm{Q}}$ & 12,1 \\
\hline V1P17 & $80-100$ & $149,6^{P}$ & $1,3^{Q}$ & 10,2 \\
\hline V1P18 & $0-19$ & $118,5^{P}$ & $1,3^{Q}$ & 23,0 \\
\hline V1P19 & $19-38$ & $192,9^{1}$ & $1,1^{\mathrm{Q}}$ & 19,0 \\
\hline V1P20 & $38-57$ & $145,9^{P}$ & $1,0^{Q}$ & 19,5 \\
\hline V1P21 & $57-76$ & $168,6^{1}$ & $1,3^{\mathrm{Q}}$ & 14,9 \\
\hline V1P22 & $76-95$ & 163,8 & $1,0^{Q}$ & 11,4 \\
\hline V1P23 & $95-114$ & $194,6^{1}$ & $1,3^{Q}$ & 17,2 \\
\hline V1P29 & $10-30$ & $119,4^{P}$ & $1,2^{Q}$ & 21,2 \\
\hline V1P28 & $40-60$ & $122,0^{P}$ & $1,3^{Q}$ & 25,3 \\
\hline V1P27 & $70-90$ & $147,5^{\mathrm{P}}$ & $1,0^{\mathrm{Q}}$ & 19,1 \\
\hline V1P26 & $100-120$ & $145,6^{P}$ & $0,7^{\mathrm{Q}}$ & 17,5 \\
\hline V1P25 & $128-148$ & $145,4^{\mathrm{P}}$ & $1,2^{Q}$ & 20,7 \\
\hline V1P24 & $160-180$ & $140,4^{\mathrm{P}}$ & $1,2^{Q}$ & 22,9 \\
\hline Amostra Base & $180-193$ & $67,6^{\mathrm{Q}}$ & $1,3^{\mathrm{Q}}$ & 15,9 \\
\hline V1P30 & $30-53$ & $179,8^{1}$ & $1,1^{\mathrm{Q}}$ & 15,2 \\
\hline V1P31 & $53-76$ & $74,3^{Q}$ & $1,3^{Q}$ & 19,9 \\
\hline V1P32 & $76-100$ & $47,3^{Q}$ & $0,7^{Q}$ & 13,0 \\
\hline \multicolumn{2}{|l|}{ Valor máximo } & 194,6 & 1,6 & 80,1 \\
\hline \multicolumn{2}{|l|}{ Valor mínimo } & 47,3 & 0,7 & 8,9 \\
\hline \multicolumn{2}{|c|}{ Referência de qualidade* } & 40 & $<0,5$ & 60 \\
\hline \multicolumn{2}{|c|}{ Prevenção* } & 45 & 1,3 & 300 \\
\hline \multicolumn{2}{|c|}{ Intervenção agrícola* } & 150 & 3 & 450 \\
\hline
\end{tabular}

Tabela 2: Teores dos metais pesados nas amostras de solo da Vereda Laçador. A tabela mostra a correlação entre atividade agrícola e concentração de metais selecionados.

* Valores orientadores da CETESB (CETESB, 2005) e CONAMA (BRASIL, 2009). QAcima dos valores de referência de qualidade. PAcima do valor de prevenção. IAcima do valor de intervenção agrícola.

referência de qualidade em apenas uma amostra.

O elevado teor de cromo e cádmio na vereda Urbano é proveniente de contribuição antropogênica, pela mesma razão das veredas Laçador e Jaraguá, mostradas anteriormente e suas fontes são as que foram mostradas nas demais veredas.

Os teores do elemento zinco presentes nos litotipos Arenitos e Argilitos analisados na Formação Três Marias, na Bacia do Rio do Formoso por Baggio (2008) demonstram que esses se encontram acima dos valores de referência para Arenito Médio extraído de Bowen (1979) e Krauskopf (1976), e acima dos valores encontrados no presente estudo, indicando que há

\begin{tabular}{|c|c|c|c|c|}
\hline \multicolumn{5}{|c|}{ Vereda Jaraguá - Uso do solo: Silvicultura } \\
\hline Amostra & \begin{tabular}{|c|}
$\begin{array}{c}\text { Profundidade } \\
(\mathrm{cm})\end{array}$ \\
\end{tabular} & $\mathrm{Cr}$ & Cd & Zn \\
\hline & & \multicolumn{3}{|c|}{$\mathrm{mg} / \mathrm{kg}$} \\
\hline V2P01 & $0-5$ & 37,8 & $0,89^{Q}$ & 25,7 \\
\hline V2P02 & $5-10$ & 37,2 & $0,92^{\alpha}$ & 13,2 \\
\hline V2P03 & $10-15$ & $40,5^{\mathrm{Q}}$ & $1,28^{\mathrm{Q}}$ & 14,6 \\
\hline V2P04 & $15-20$ & $45,9^{Q}$ & $0,92^{Q}$ & 13,5 \\
\hline V2P05 & $20-25$ & $62,3^{Q}$ & $0,85^{Q}$ & 17,1 \\
\hline V2P06 & $25-30$ & $71,2^{Q}$ & $0,79^{Q}$ & 15,7 \\
\hline V2P07 & $30-35$ & $66,6^{\mathrm{Q}}$ & $0,64^{Q}$ & 15,6 \\
\hline V2P08 & $35-40$ & $98,3^{P}$ & $1,03^{Q}$ & 25,4 \\
\hline V2P09 & $40-45$ & $81,2^{P}$ & $0,90^{Q}$ & 14,9 \\
\hline V2P10 & $45-50$ & $104,1^{\mathrm{P}}$ & $1,16^{Q}$ & 10,5 \\
\hline V2P11 & $50-55$ & $84,9^{P}$ & $1,07^{Q}$ & 12,1 \\
\hline V2P12 & $55-60$ & $101,8^{P}$ & $0,73^{Q}$ & 9,9 \\
\hline V2P13 & $60-65$ & $90,3^{P}$ & $0,85^{\mathrm{Q}}$ & 11,4 \\
\hline V2P16 & $0-5$ & $91,6^{P}$ & $1,21^{Q}$ & 15,8 \\
\hline V2P17 & $5-10$ & $74,1^{\mathrm{Q}}$ & $1,07^{\mathrm{Q}}$ & 15,3 \\
\hline V2P18 & $10-15$ & $89,8^{\mathrm{P}}$ & $0,99^{Q}$ & 27,9 \\
\hline V2P20 & $15-20$ & $171,3^{\prime}$ & $1,61^{\mathrm{Q}}$ & 33,4 \\
\hline V2P21 & $20-25$ & $42,1^{\mathrm{Q}}$ & $1,14^{\mathrm{Q}}$ & 18,9 \\
\hline \multicolumn{2}{|c|}{ Valor máximo } & 171,3 & 1,61 & 33,4 \\
\hline \multicolumn{2}{|c|}{ Valor mínimo } & 42,1 & 0,64 & 8,9 \\
\hline \multicolumn{2}{|c|}{$\begin{array}{ll}\begin{array}{l}\text { Referência } \\
\text { qualidade }\end{array} & \text { de } \\
\end{array}$} & 40 & $<0,5$ & 60 \\
\hline \multirow{2}{*}{\multicolumn{2}{|c|}{ Prevenção }} & 45 & 1,3 & 300 \\
\hline & & 150 & 3 & 450 \\
\hline
\end{tabular}

Tabela 3: Teores dos metais pesados nas amostras de solo da Vereda Jaraguá. A tabela mostra a correlação entre silvicultura e concentração de metais selecionados.

* Valores orientadores da CETESB (CETESB, 2005) e CONAMA (BRASIL, 2009). QAcima dos valores de referência de qualidade. ${ }^{P}$ Acima do valor de prevenção. ${ }^{I}$ Acima do valor de intervenção agrícola.

enriquecimento deste metal nos solos da Bacia.

Essa alteração no teor de zinco pode estar associada também ao uso e ocupação do solo que acontece na porção jusante da Bacia, área destinada à agricultura comercial, pastagens, agroindústria e bovinocultura intensiva.

\section{CONCLUSÕES}

Os resultados das análises de metais permitiram estabelecer as condições ambientais dos solos das veredas Laçador, Jaraguá e Urbano na Bacia do Rio do Formoso. Pode-se concluir que os teores de metais pesados encontrados nos solos das veredas demandam atenção tendo em vista que boa parte deles supera os limites de prevenção estabelecidos pela CETESB e os limites de intervenção descritos pela Resolução CONAMA 420/2009.

A proximidade destas veredas com áreas que são intensamente utilizadas por atividades agrosilvopastoris 


\begin{tabular}{|c|c|c|c|c|}
\hline \multicolumn{5}{|c|}{ Vereda Urbano - Uso do solo: Pastagem } \\
\hline Amostra & Profundidade $(\mathrm{cm})$ & $\mathrm{Cr}$ & $\mathbf{C d}$ & $\mathrm{Zn}$ \\
\hline & & \multicolumn{3}{|c|}{$\mathrm{mg} / \mathrm{kg}$} \\
\hline V3P01 & $39-52$ & $76,1^{\mathrm{P}}$ & $1,0^{\mathrm{Q}}$ & 33,7 \\
\hline V3P02 & $29-35$ & $121,2^{P}$ & $0,6^{Q}$ & 47,0 \\
\hline V3P03 & $9-23$ & 205,4 & $0,8^{\mathrm{Q}}$ & 47,9 \\
\hline V3P04 & $0-20$ & $30,1^{Q}$ & $0,8^{Q}$ & 20,1 \\
\hline V3P05 & $20-40$ & $47,4^{\mathrm{Q}}$ & $1,3^{Q}$ & 28,6 \\
\hline V3P06 & $48-65$ & $47,9^{Q}$ & $0,9^{Q}$ & $60,7^{\mathrm{Q}}$ \\
\hline V3P07 & $76-96$ & $59,7^{Q}$ & $0,7^{Q}$ & 27,0 \\
\hline \multicolumn{2}{|c|}{ Valor máximo } & 205,4 & 1,3 & 60,7 \\
\hline \multicolumn{2}{|c|}{ Valor mínimo } & 30,1 & 0,6 & 20,1 \\
\hline \multicolumn{2}{|c|}{ Referência de qualidade } & 40 & $<0,5$ & 60 \\
\hline \multicolumn{2}{|c|}{ Prevenção } & 45 & 1,3 & 300 \\
\hline \multicolumn{2}{|c|}{ Intervenção agrícola } & 150 & 3 & 450 \\
\hline
\end{tabular}

Tabela 4: Teores dos metais pesados nas amostras de solo da Vereda Urbano. A tabela mostra a correlação entre atividade agropastoril e concentração de metais selecionados.

* Valores orientadores da CETESB (CETESB, 2005) e CONAMA (BRASIL, 2009). QAcima dos valores de referência de qualidade. PAcima do valor de prevenção. IAcima do valor de intervenção agrícola

sugerem que a origem dos metais analisados pode ser de tais atividades.

\section{AGRADECIMENTOS}

Ao $\mathrm{CNPq}$ pelo financiamento desta pesquisa e ao Centro de Pesquisa Manoel Teixeira da Costa CPMTC/IGC/UFMG e a pós-graduação em geologia pelo apoio logistico.

\section{REFERÊNCIAS BIBLIOGRÁFICAS}

BAGGIO, H.F. 2008. Contribuições naturais e antropogênicas para a concentração e distribuição de metais pesados em água superficial e sedimento de corrente na Bacia do Rio do Formoso, município de Buritizeiro, MG. Tese de Doutorado, Instituto de Geociências, Universidade Federal de Minas Gerais, 249 p.

BOAVENTURA, R. S. 1981. Características geomorfológicas In: Melo, D. R. 1992. As veredas nos planaltos do noroeste mineiro; caracterização pedológicas e os aspectos morfológicos e evolutivos. Dissertação de Mestrado, Instituto de Geociências e Ciências Exatas, Universidade Estadual Paulista, 218 p.

BOWEN, J. M. H. 1979. Environmental Chemistry of the Elements. London: Academies Press, 273 p.

CETESB. Decisão de diretoria No $195-2005-\mathrm{E}$, de 23 de novembro de 2005. São Paulo, CETESB. 2005. 4 p.;

CONAMA, 2009. Conselho Nacional do Meio Ambiente - Resolução CONAMA n ${ }^{\circ} 420$, de 28 de dezembro de 2009.

EMBRAPA. 1997. Centro Nacional de Pesquisas de Solos. Rio de Janeiro, RJ. Manual de Métodos de Análise de Solo, 2 ed. rev. atual, Rio de Janeiro: Centro Nacional de Pesquisas de Solos, $212 \mathrm{p}$.

ENVIRONMENTAL PROTECTION AGENCY. 1994. Method 3051- Microwave assisted acid digestion of sediments, sludges, soils and oils. Washington D.C. 14 p.

KIEKENS, L. Z. 1995. Heavy metals in soils. In: Alloway, B. J. 1990. (Ed). Glasgow: Black and Son, 261-277 p.

KRAUSKOPF, K, B. 1976. Introduction to geochemistry. New York: McGraw-Hill. 721 p.
MELO, D. R. 1992. As veredas nos planaltos do noroeste mineiro; caracterização pedológicas e os aspectos morfológicos e evolutivos. Dissertação de Mestrado, Instituto de Geociências e Ciências Exatas, Universidade Estadual Paulista, 218 p.

VIANA, V. M. F. C. 2006. Estudo Hidrogeoquímico das Veredas do Rio do Formoso no Município de Buritizeiros, Minas Gerais. Dissertação de Mestrado, Instituto de Geociências, Universidade Federal de Minas Gerais, 107 p. 